\title{
Preliminary Characterization OF The Rivet Shaving Process
}

\author{
Ruben Montaño-Vega, Moises Batista Ponce, Francisco Jose Leon Arevalo, Raul \\ Ruiz-Garcia, Luis Roldan Jimenez, Irene del Sol Illana, Jorge Salguero Gomez
}
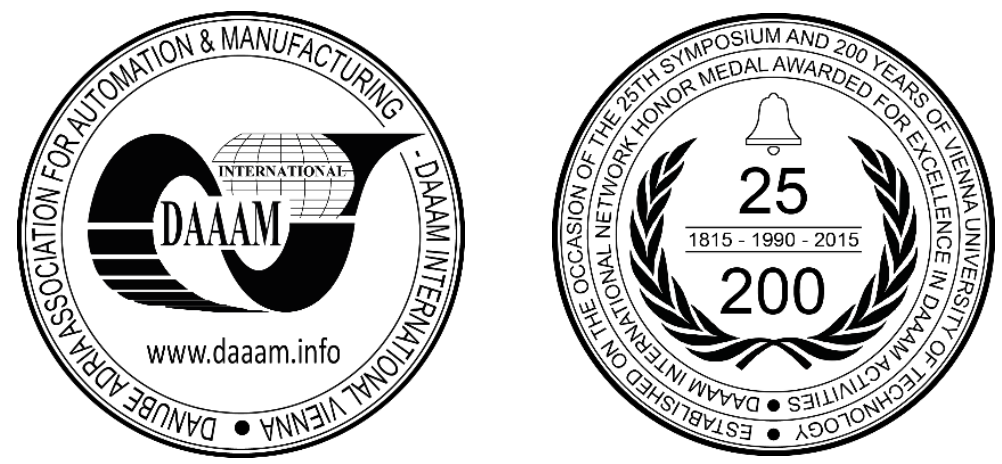

This Publication has to be referred as: Montano-Vega, R[uben]; Batista Ponce, M[oises]; Leon Arevalo, F[rancisco] J[ose]; Ruiz-Garcia, R[aul]; Roldan Jimenez, L[uis]; del Sol Illana, I[rene] \& Salguero Gomez, J[orge] (2018). Preliminary Characterization of the Rivet Shaving Process, Proceedings of the 29th DAAAM International Symposium, pp.1116-1124, B. Katalinic (Ed.), Published by DAAAM International, ISBN 978-3-902734-20-4, ISSN 1726-9679, Vienna, Austria

DOI: $10.2507 / 29$ th.daaam.proceedings. 159

\begin{abstract}
Assembly is one of the most important stages in the aeronautical sector. Among the different joining technologies involved during this process, the mechanical union by riveting is the most commonly used. At the same time there are some types of blind rivets which entail a problem with respect to aerodynamic and design. In particular, an excess shank protrudes over the rivet head and has to be removed by an operation known as rivet shaving. Conventionally, rivet shaving is done manually by an operator, with the consequent drawbacks that this entails in terms of repetitiveness, production times, functional performance, etc. Concerning that, nowadays there is a tendency to rivet shaving automation. To do it effectively, it is necessary a complete characterization of the process because of the absence of technical information about it. Therefore, in the present paper is going to be described a series of experiments in which have been analysed the tool wear mechanisms and the cutting forces obtained during a series of preliminary tests. Finally, thanks to the acquired knowledge, it is going to be possible to facilitate the design of robots and machines which will be able to complete the operation automatically and will facilitate their insertion within the industry.
\end{abstract}

Keywords: rivet shaving; aeronautical sector; automation; tool wear; cutting forces

\section{Introduction}

Rivet shaving can be defined as the machining operation in charge of removing the excess of a threaded blind rivet after it has been installed (Fig. 1.), in order to prevent this excess from emerging with respect to the surface. This ensures that the parts are within the required dimensional tolerances and also prevents these excess shanks from interfering with the aerodynamics of the aircraft, when it comes to parts of the fuselage.

This is a process of which there is not much information, although it is an operation that is carried out industrially, especially within the aeronautical sector. This means that it is an operation whose knowledge is not disseminated, so that many parameters and characteristics of that process are not properly studied. Previous to this study only isolated papers [1], [2], [3] and some patents [4], [5], [6], [7], [8] could be found. But it is not have been spread neither a general nor a specific knowledge about this operation. That is why, it is said that there exists a lack of information about it. 
On the other hand, nowadays there are important companies of the aeronautical sector that are concerned about the rivet shaving process automation, but there exists a lack of information about this machining operation. A good detail to realize the impact that the automation of this process can have is that a medium-sized aircraft counts approximately with 85,000 rivets [9], of which 400 rivets need to be shaved. Authors like Barry et al. [1], [2], [3] have developed automatic solutions, but it has been mainly done through machines of great size and low flexibility which requires a great investment. However, nowadays it is not what companies need [10]. A direct solution to make easier the transition to this goal is to make a complete characterization of the process by means of an experimental methodology. In this sense, in this paper prior to the experimental methodology development have been completed some preliminary experiments through which it is going to be shown new results and information about the rivet shaving operation.

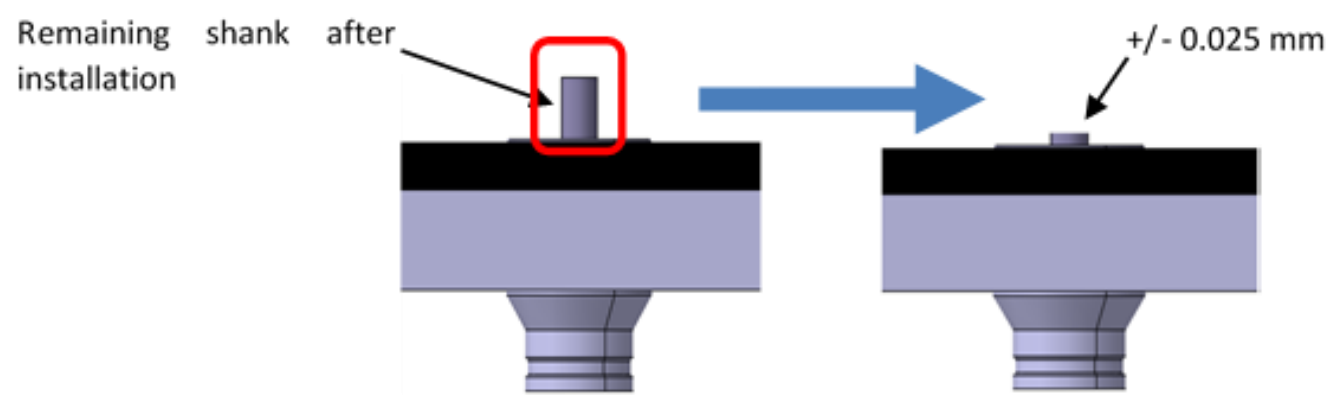

Fig. 1. Remaining shank which needs to be removed after rivet installation

The threaded blind rivets are usually composed of the following parts of Fig. 2. As it was mention before, this type of rivets involves a problem, an excess shank protrudes over the rivet head and need to be removed by a machining operation, known as rivet shaving.

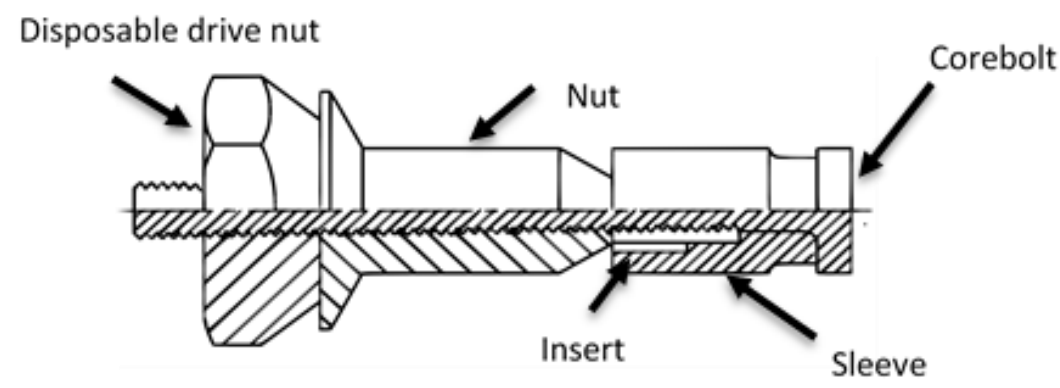

Fig. 2. Threaded blind rivets parts

Knowing the problem that this types of rivets entails, according to the information consulted in [3], it can be observed that the only requisite demanded in terms of quality of the operation is a dimensional control. As it is shown, after the process is completed, the shank dimensions need to be within a tolerance range, normally of $+/-0.025$ (mm) [2]. Among the different parts shown in Fig. 2. the corebolt is the one which needs to be machined, and therefore the one which has more interest from rivet shaving point of view. Specifically, one of the material most used to compose the corebolt is the alloy A-286 [11], [12], [13], due to the good mechanical properties that gives to the rivet and its good resistance at high temperature [14]. Thereby, the analysis of the rivet shaving process is going to be developed through this alloy, due to it is considered the most representative. Next, we are going to talk about one of the most used technologies to perform this operation. In particular, the one used by the machine Zephyr 507C, design and made by Zephyr manufacturer. It is one of the manual tools most used by the different companies in the aeronautical sector due to its excellent results in machining operations. This is shown together with an example of a cutting tool compatible with that machine in Fig. 3 . If we focus on the cutting technology used by this machine, it is essentially a milling process, except that it involves an extra movement to obtain better finishing conditions. Specifically, a one-piece milling cutter with geometry similar to a cylindrical milling cutter performs a series of movements as it is shown. There exists a double rotation of the cutting tool plus a feed movement that is usually done longitudinally or transversally with respect to the rivet shank, as it is shown. So this operation is usually executed following a vertical trajectory or a horizontal trajectory. In that way, from now on this technology is going to be known as combined motion milling process. 

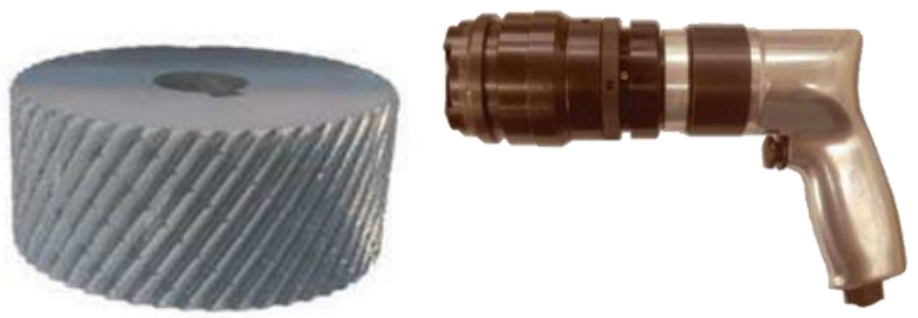

Fig 3. Zephyr 507C rivet shaver and an example of compatible tool [12]

If we focus on the vertical trajectory, when the operator executes it, he must make a push force towards the rivet, similar to what happens in manual drilling operations. In addition, when executing the operation, the operator must support lateral forces in the XY plane, so that the tool tends to leave the machining area. A scheme of the above commented can be seen in Fig. 4.

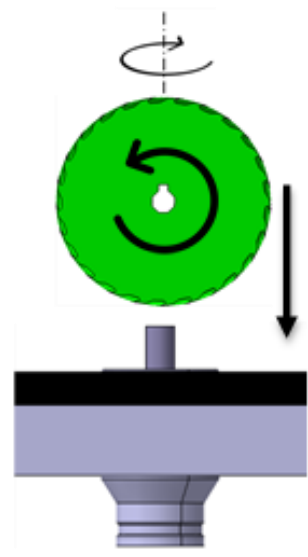

Vertical trajectory

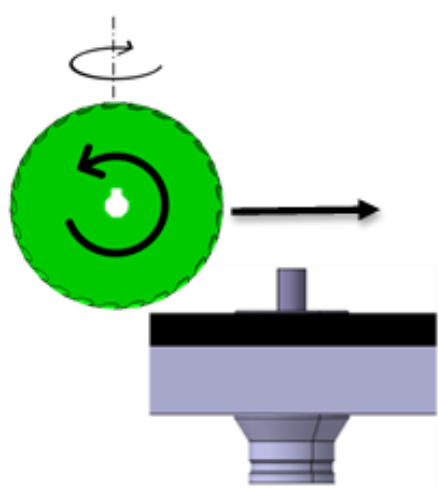

Horizontal trajectory

Fig. 4. Machining strategies in the combined motion milling process

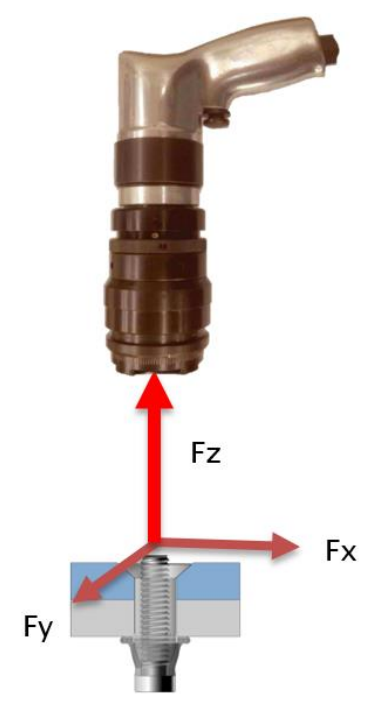

Fig. 5. Forces during shaving operation

As it was said above, since rivets with A-286 steel core are one of the most used in the aeronautical sector, it can be said that they are the most representative case. Bearing this in mind, a series of aspects of the operation will be described. According to the manufacturer Zephyr, there are a series of models of cutting tools, all of them composed of tungsten carbide. To find out if this material is valid when machining A-286 steel, it has been carried out a bibliographic search about the machining of this alloy regardless to the type of operation. As can be seen in Table 1. it has been verified that in general terms tungsten carbide with TiAlN coating is generally the most used. So this material is considered suitable for this purpose. 


\begin{tabular}{|c|l|l|}
\hline Reference & \multicolumn{1}{|c|}{ Paper Title } & \multicolumn{1}{|c|}{ Cutting tool material } \\
\hline$[\mathbf{1 5}]$ & $\begin{array}{l}\text { Micro-machinability of A-286 Steel with and without Laser } \\
\text { Assist }\end{array}$ & $\begin{array}{l}\text { Carburo de Wolframio/Tungsteno con } \\
\text { recubrimiento TiAlN }\end{array}$ \\
\hline$[\mathbf{1 6}]$ & Environmental-friendly turning of A286 superalloy & Carburo de Wolframio/Tungsteno \\
\hline$[\mathbf{1 7}]$ & $\begin{array}{l}\text { The modified surface properties and fatigue life of Incoloy } \\
\text { A286 face-milled at different cutting parameters }\end{array}$ & $\begin{array}{l}\text { Carburo de Wolframio/Tungsteno con } \\
\text { recubrimiento TiAlN }\end{array}$ \\
\hline \multirow{2}{*}[\mathbf{18}]{} & $\begin{array}{l}\text { Performance of ceramic tools in high-speed cutting iron- } \\
\text { based superalloys }\end{array}$ & Ceramic: Sialon \\
\cline { 3 - 3 } & & Ceramic: Al2O3+SiCw \\
\cline { 3 - 3 } & & Ceramic: A12O3+Ti(C,N) \\
\hline
\end{tabular}

Table 1. Materials used for machining A-286 Steel according to bibliography

Similarly, it was searched information about the wear of tungsten carbide tools during the machining of alloy A-286. There no exist articles or books referring to the "shaving" of this alloy, then it has been sought information about other types of operations such as turning or milling of this material.

In this way, it has been found that the wear mechanisms that usually take place are:

- Mechanical failure, in the form of chipping, mainly due to the high tenacity of the material. The properties of high strength, mechanical hardening and adhesion hardening result in notch wear and an extremely abrasive environment for the edge. The tendency for notch wear to form on the edge increases as the cutting depth increases [19], [20].

- Adhesion, mainly of secondary or indirect type. In particular, these appear in the form of a layer adhered to the flank face (BUL) and a cutting edge (BUE) [21]. This is especially true for dry machining [18].

- Abrasion. The high resistance of alloy A-286, together with the mechanical hardening of the part after machining, create an extremely abrasive environment.

- Corrosion and diffusion wear, which are accentuated due to the high temperatures generated in the cutting area [19], [22].

As the authors Musavi et al. indicate in [16], due to the high temperatures that are created during the machining of this alloy, the application of some type of refrigeration can become very interesting. In particular, tool life can be increased up to $200 \%$. Finally, as it was mentioned previously, rivet shaving is a machining operation that is executed entirely manually, and nowadays there exists a trend towards its automation.

However, solutions that provide flexibility are preferred to large-scale machines such as automatic gantries [1], [2], [3], with very little flexibility and very high costs. Thus, there is a trend towards the use of robotic arms and tricept-type robots with heads adapted to each need [23]. To dimension them, it is necessary to know more details about the process, however there exists a lack of information which justify the goal of this paper, a complete characterization of the rivet shaving process. In this way, in addition to the information gathered, some preliminary experiments carried out will be analysed.

\section{Experimental Procedure}

In this section, the different elements used during the preliminary tests will be described. A Kistler 9255b Dynamometer was placed on a Heller FTC 1000 universal milling machine to carry out the experiments (see Fig. ). This Dynamometer was bolted to the table area of the Heller milling machine and the riveted workpiece was then placed and fixed on the Kistler Dynamometer. Then, for the signal acquisition, a Kistler 5019b signal conditioner was connected to the Kistler dynamometer table. At the same time, these devices were connected to a computer with the LabVIEW software installed and prepared to capture and save the force signals that would be generated during the tests. The set of equipment used for the acquisition of signals can also be observed in Fig.

Once the set of equipment required to perform the test had been assembled, the Zephyr 507C tool was connected to an air intake at 6 bar pressure. The threaded blind rivet selected for the tests was a Composi-Lok II, from the manufacturer MONOGRAM, made of the following materials shown in Table 2.

\begin{tabular}{|c|c|}
\hline Parts & Material \\
\hline Corebolt & A-286 Alloy \\
\hline Insert & Acetal \\
\hline Nut & Ti6Al4V \\
\hline Sleeve & AISI 304 \\
\hline
\end{tabular}

Table 2. Materials forming the selected rivet 
Finally, it was used a custom-made tungsten carbide and cobalt tool from Zephyr Manufacturer [24]. This tool had 37 cutting edges and a diameter of $28.5(\mathrm{~mm})$. Then, with all the equipment correctly positioned and connected, the shaving tests were performed manually, as shown in Fig. 6. In this case, a combined motion milling was performed following a vertical strategy by means of a Zephyr 507C machine. Considering this, in the results the $\mathrm{Z}$ component of the force must have a significant magnitude with respect to the resulting total force, as mentioned above. Finally, once the four tests had been completed, the signals were saved using LabVIEW software and then an analysis of the most relevant data was carried out.

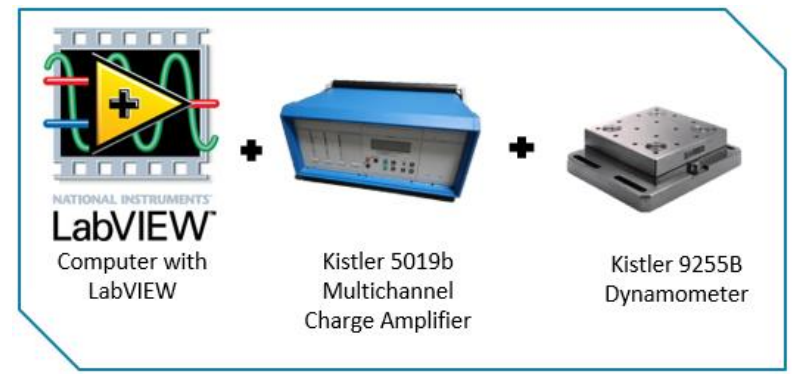

(a)

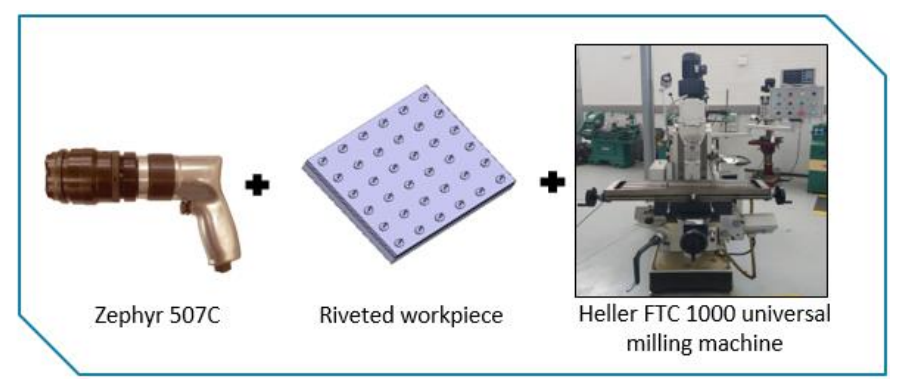

(b)

Fig. 6. Elements for the execution of the tests. (a) Equipment for signals acquisition; (b) Elements for machining

Finally, after the execution of the tests, the worn tool provided by the collaborating company was evaluated. The evaluation was carried out using a Nikon SMZ800 stereoscopic microscope.

\section{Results}

\subsection{Forces analysis}

Once the assembly of the different equipment used has been described, this section will show the results obtained during these tests. Four shaving tests were carried out to characterize the forces that exist during the operation. Each of them was carried out manually and following vertical trajectories as can be seen in Fig. 6 .

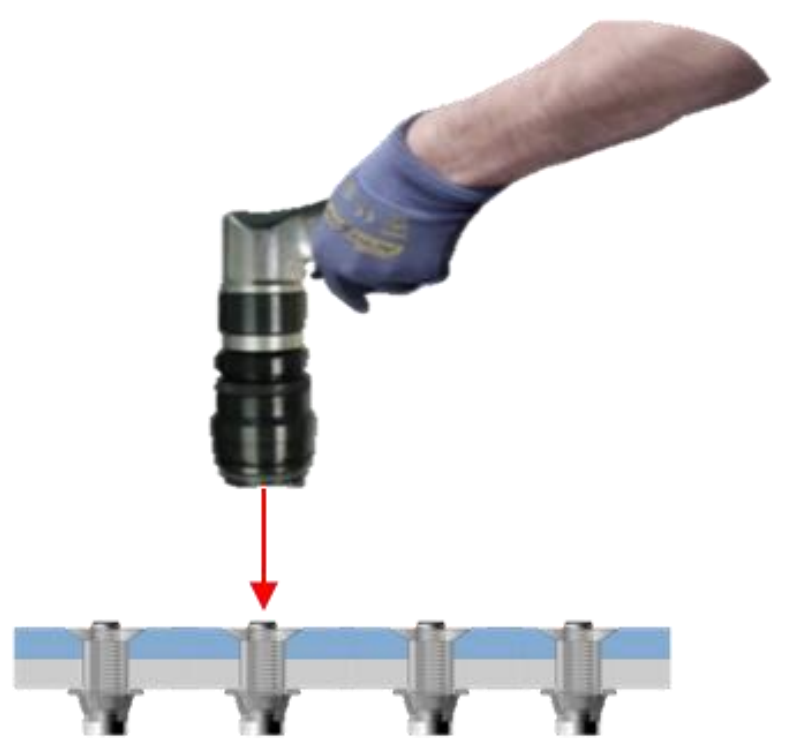

Fig. 7. Diagram of the four tests carried out

As mentioned in the previous section, the forces were obtained like signals, some of which are shown in the graphs in Fig. and Fig. . From the analysis of these signals, were obtained the maximum values of the amplitudes of the most relevant forces, obtaining the data from Table 3. When the Fmax and Fz,max forces of the Table 3. are observed, it can be seen that there exists important differences among them. This could be explained by the fact that all tests were performed manually and it is known that there is no repeatability in manual operations. It can also influence aspects such as trajectories, which will not be completely vertical so the values of the force components could vary in each case. 


\begin{tabular}{|c|c|c|}
\hline Test & Maximum Resulting Force, Fmax (N) & Maximum Z-axis force, Fz,max (N) \\
\hline $\mathbf{1}$ & 14,14 & 19,56 \\
\hline $\mathbf{2}$ & 59,30 & 40,77 \\
\hline $\mathbf{3}$ & 13,05 & 29,74 \\
\hline $\mathbf{4}$ & 17,09 & 7,08 \\
\hline
\end{tabular}

Table 3. Test results

From the previous data, it can be observed that the force in $\mathrm{Z}$ is very significant and has an important maximum amplitude of up to $40 \mathrm{~N}$. This coincides with what was mention before, where it was estimated that when a vertical trajectory is chosen and the tool is forced to machine along that path, the thrust force must be of great importance. In addition, the resulting force, which is ultimately the force that the robot intended to perform the operation will have to withstand, can be of high magnitudes, specifically reaching up to $60 \mathrm{~N}$ during test 2, as can be seen in Table 3 .

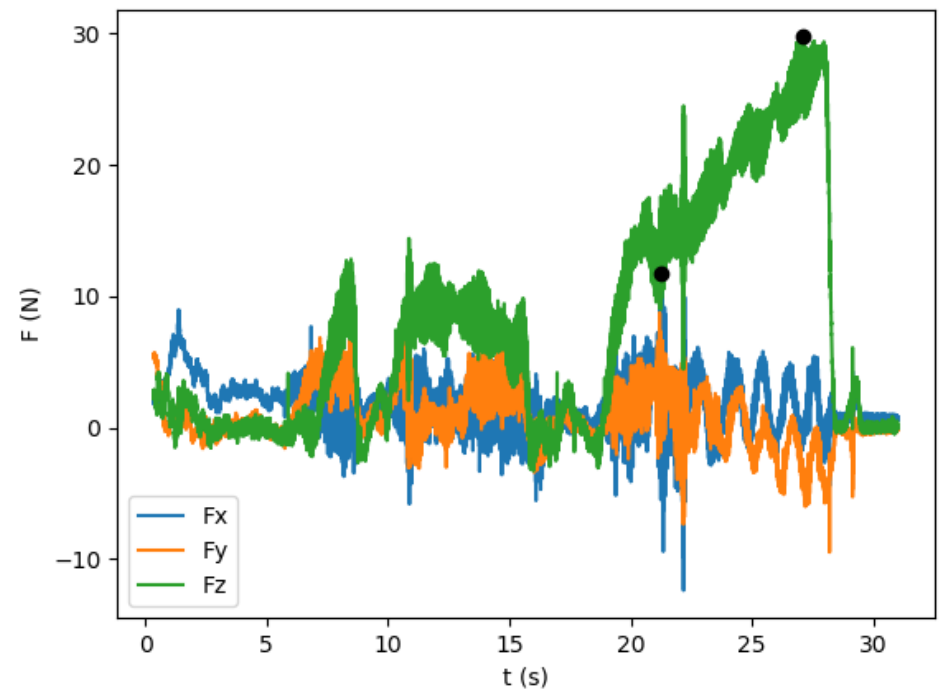

Fig. 8. X, Y, Z force components as a function of time (test 3)

On the other hand, it is observed in Fig. .b that the forces in $\mathrm{X}$ and $\mathrm{Y}$ are of minor magnitudes, but it should be noted that punctual peaks of up to +/- $15 \mathrm{~N}$ can appear. Thus, a variation of up to $30 \mathrm{~N}$ is experienced in these axes, which will cause the tool to be pushed out of the rivet due to these lateral forces originated in the XY plane. In addition, as shown in Fig. 9.a. these forces have been broken down into radial and normal components with respect to the rotation of the tool, but there are hardly any noticeable differences.

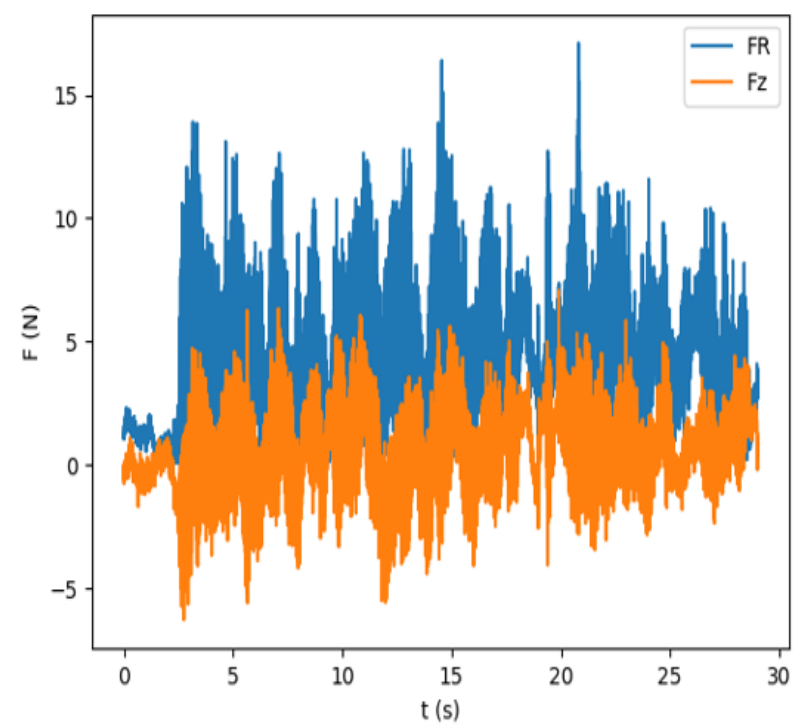

(a)

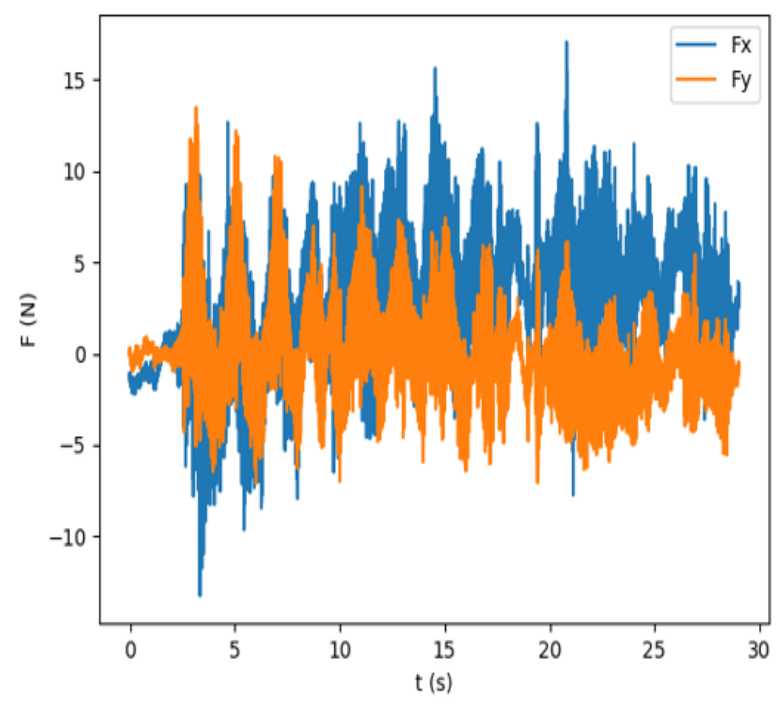

(b)

Fig. 9. Signals obtained in test 4. (a) radial and normal forces; (b) $\mathrm{x}$ and y forces 


\subsection{Tool wear mechanisms}

Next, we are going to analyze the tool wear mechanisms that appear in the operation thanks to a company in the aeronautical sector supplied us with a worn shaving tool. This had been used in manual shaving operations of rivets with shank made of A-286. The number of shavings performed with it is unknown, but it is known that it is worn and at the end of its useful life. The tool provided can be seen in Fig. .

First of all, macrographies were taken of the areas of the tool where a more relevant wear is observed by means of the Nikon SMZ 800 stereoscopic microscope. They are shown in Fig. at a magnification of x10 and x20.

The wear observed in the tool will be compared with the wear mechanisms that usually appear when machining alloy A286, which were compiled from the different bibliographical references [15], [17], [19]. Taking into account the bibliography when analysing the macrographies, it has been observed the following wear mechanisms:

- Mechanic failure. It is located in the form of non-uniform chipping, in random locations, in the same way as indicated in ISO 8688. This is shown in pictures (b), (c) and (d) in Fig. .

- Adhesion. In the same way as wear due to mechanical failure, this is a wear that usually appears when machining alloy A-286. It is mentioned that this wear is accentuated by two phenomena, the high machining temperatures and second by the chemical affinity between tool and part. This can be seen in images (a), (b) and (c), in Fig. 11.

- Abrasion. In this case, we can observe areas where there are abrasion wear, as in images (a) and (c) in Fig. 11.
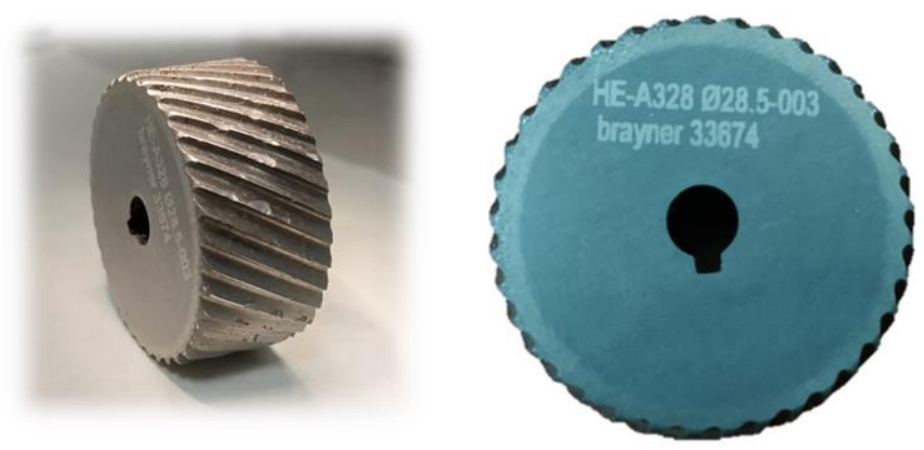

Fig. 10. Worn shaving tool provided

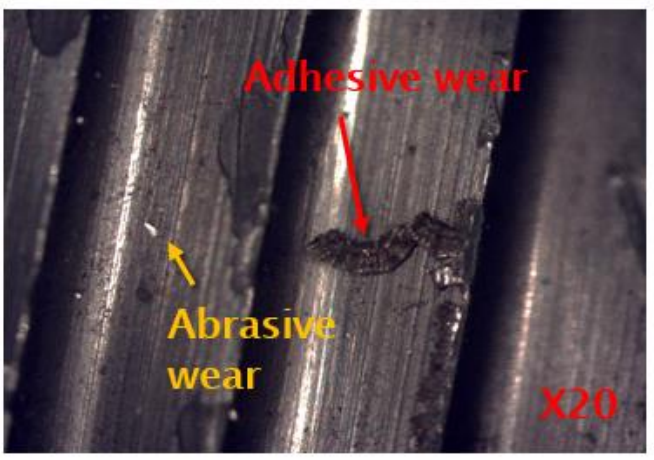

(a)

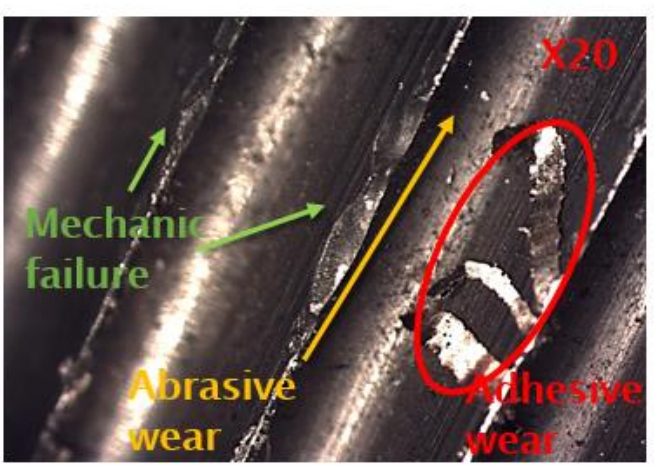

(c)

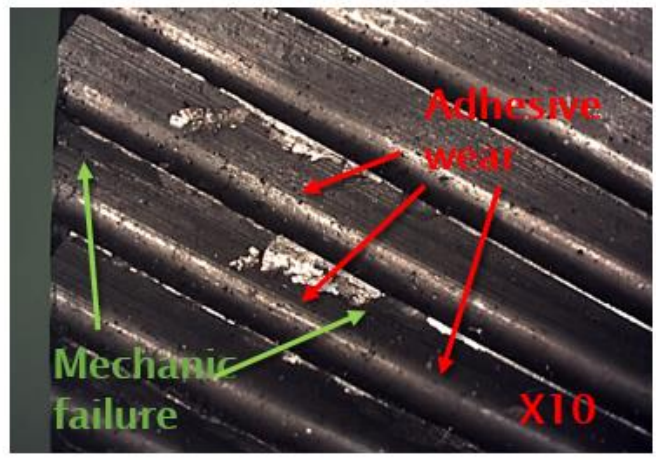

(b)

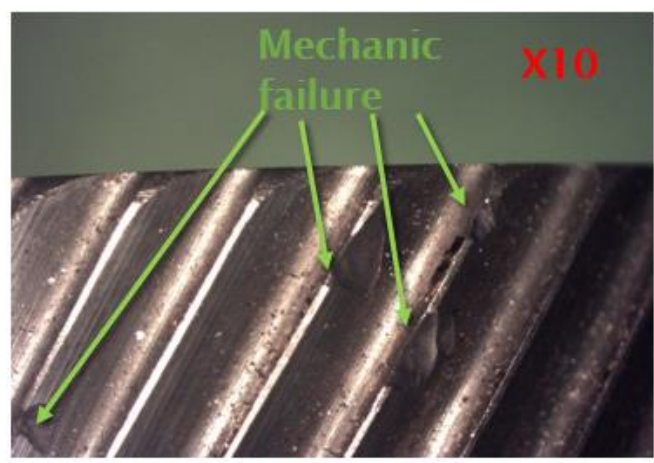

(d)

Fig. 11. Tool wear mechanisms in the shaving tool provided 
In order to know the magnitude of chipping wear, it has been taken four measurements of the chipping size, which can be observed in Table 4. And Fig. 12. The measurements have been taken with the free software ImageJ.

\begin{tabular}{|c|c|c|c|}
\hline $\mathbf{M 1}(\mathbf{m m})$ & $\mathbf{M 2}(\mathbf{m m})$ & $\mathbf{M 3}(\mathbf{m m})$ & $\mathbf{M 4}(\mathbf{m m})$ \\
\hline 0.422 & 0.433 & 0.338 & 0.231 \\
\hline
\end{tabular}

Table 4. Measurements of parameter VB taken on the shaving tool

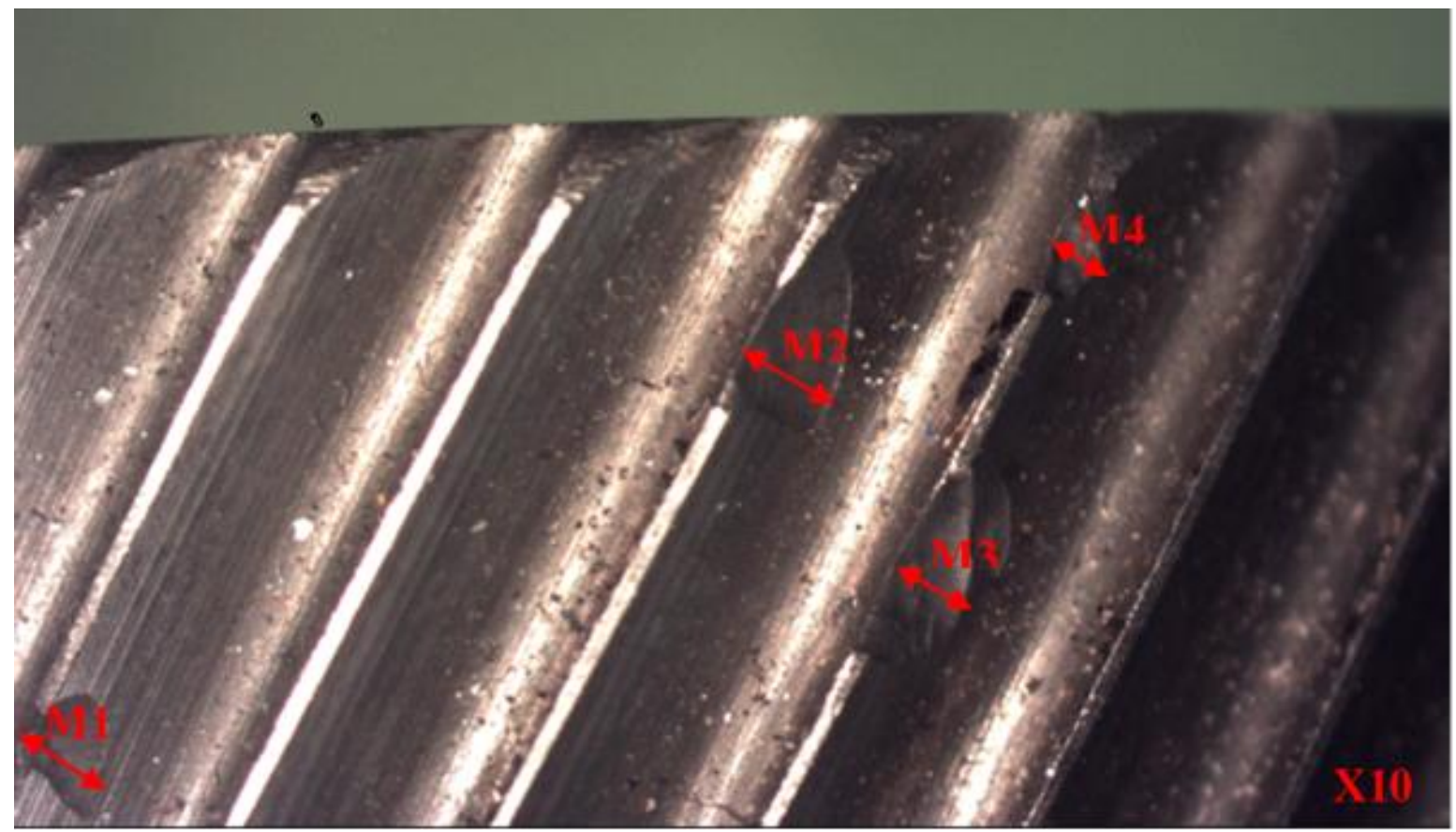

Fig. 12. Measurements of the chipping size

\section{Conclusions}

As has been proven throughout the search for information on the rivet shaving operation, there is a significant lack of knowledge. Thus, in view of the current automation needs of some companies in the aeronautical sector, new details on rivet shaving have been obtained through the different tests and evaluations. This will facilitate the contextualization and design of a future experimental methodology that will allow the characterization of the process.

Among the information collected, it has been analysed the combined motion milling process, the one most used for rivet shaving in the aeronautical sector. It is the technology employed by the Zephyr 507C machine and it permits to obtain a very good finishing results. Considering that rivets with A-286 steel core are one of the most used in the aeronautical sector, it has been found that tungsten carbide tools seem to be a good solution as it is indicated in the bibliography.

On the other hand, throughout the forces analysis can be concluded that during combined motion milling process with vertical strategy, the $\mathrm{Z}$ component of the forces has a significant importance. Although, the components in the XY plane cannot be forgotten. Also, some forces values have been obtained, being $60 \mathrm{~N}$ the maximum in $\mathrm{Z}$ component, and a range of $30 \mathrm{~N}$ in the forces which take place in the XY plane. For the first time, the wear mechanisms of a cutting tool designed for shaving rivets of A-286 material have been analysed, observing that there are mainly mechanical failures, adhesion and abrasion. Despite the lack of information on this operation, sufficient information has been collected to carry out and analyse preliminary tests, which have yielded new results in this respect. Among other things, they will facilitate the automation of the rivet shaving process.

Finally, the next step after this research is, from the results obtained here, to develop and carry out an experimental methodology to make a more complete and detailed characterization of the rivet shaving process.

\section{Acknowledgments}

This research was funded by the Department of Mechanical Engineering and Industrial Design of the University of Cadiz. Thanks to the Area of Engineering of the Manufacturing Processes and to the School of Engineering, for providing the facilities for the accomplishment of the tests and evaluations. Thanks to the company Airbus for the information and tools provided for the completion of the research. 


\section{References}

[1] J. P. Barry, P. B. Zieve, R. T. Meador, y B. Conley (2000). «Electric 30,000 RPM Shave Spindle for C Frame Riveter and High Performance Compact Aerospace Drill», Automated Fastening Conference \& Exposition.

[2] Todd Rudberg and Scott Smith (2001). «Method of Accurate Countersinking and Rivet Shaving», American Technical Publishers LTD, vol. 110, pp. 166-172.

[3] D. Remley, J. Rediger, P. Haworth, y R. Holden (2009). «Slug Rivet Machine Installs 16 Rivets Per Minute DrillRivet-Shave», Aerospace Technology Conference and Exposition.

[4] Jr Arnaud P. Bipart (1959), «Metal Shaving Tool», U.S. Patent US2910920A.

[5] B. Grille Sacaluga y F. Torres Pineda (2009). «Cabezal de fresado de los vástagos de remaches», Spanish patent number: 200701064.

[6] Arthur R. Skaran (1960). «Shaving Tool», U.S. Patent US2919631A.

[7] Plester Joseph (1951). «Tool for shaving down local protuberances», U.S. Patent US2919631A.

[8] Juan Ramón Astorga Ramírez y Juan Francisco García Amado (2010). «Sistema de repasado orbital post-afeitado de remaches», International Patent PCT/ES2009/070208.

[9] A. Morales, F. Puerta, F. Bañón, y J. Salguero (2018). «Optimización del proceso de taladrado dentro del contexto de la Industria 4.0». Available from: https://www.interempresas.net/Portada/Articles/207043-Optimizacion-delproceso-de-taladrado-dentro-del-contexto-de-la-Industria-40.html. Accessed: 2018-10-07.

[10] Grube Hansen, D.; Malik, A. A. \& Bilberg, A. (2017). Generic Challenges and Automation Solutions in Manufacturing SMEs, Proceedings of the 28th DAAAM International Symposium, pp.1161-1169, B. Katalinic (Ed.), Published by DAAAM International, ISBN 978-3-902734-11-2, ISSN 1726-9679, Vienna, Austria.

[11] F.C. Campbell (2006). Manufacturing Technology for Aerospace Structural Materials, Elsevier, ISBN: 978-185617-495-4.

[12] Delta International Inc., «Quality Tools for the Aviation industry. Zephyr Model ZT507C». Available from: http://www.deltaintl.com/Material\%20removal/Material\%20Removal\%20Model\%20ZT507C.html. Accessed: 2018-10-07.

[13] Monogram, «Monogram Aerospace Fasteners». Available from: http://www.monogramaerospace.com/\#. Accessed: 2018-10-07.

[14] «Alloy A-286». Available from: https://www.aircraftmaterials.com/data/alstst/A286.html. Accessed: 2018-10-07.

[15] A. Bucciarelli, P. D. Kuila, S. N. Melkote, y A. Fortunato (2016). «Micro-machinability of A-286 Steel with and without Laser Assist», Procedia CIRP, vol. 46, pp. 432-435.

[16] S. H. Musavi, B. Davoodi, y S. A. Niknam (2018). «Environmental-friendly turning of A286 superalloy», Journal of Manufacturing Processes, vol. 32, pp. 734-743.

[17] G. Liu, C. Huang, H. Zhu, Z. Liu, Y. Liu, y C. Li (2017). «The modified surface properties and fatigue life of Incoloy A286 face-milled at different cutting parameters», Materials Science and Engineering: A, vol. 704, pp. 1-9.

[18] X. Tian, J. Zhao, W. Qin, F. Gong, Y. Wang, y H. Pan (2017). «Performance of ceramic tools in high-speed cutting iron-based superalloys», Machining Science and Technology, vol. 21, n. ${ }^{\circ}$ 2, pp. 279-290.

[19] L. N. López de la Calle, J. A. Sánchez Galíndez, y A. Lamikiz Menchaca (2004). Mecanizado de Alto Rendimiento, Ediciones Técnicas Izaro, ISBN: 84-609-1380-5.

[20] «Superaleaciones termorresistentes (HRSA)». Available from: https://www.sandvik.coromant.com/sitecollectiondocuments/downloads/global/technical guides/es-es/c-2920034.pdf. Accessed: 2018-10-07.

[21] A. Gómez-Parra, M. Álvarez-Alcón, J. Salguero, M. Batista, y M. Marcos (2013) «Analysis of the evolution of the Built-Up Edge and Built-Up Layer formation mechanisms in the dry turning of aeronautical aluminium alloys», Wear, vol. 302, n. ${ }^{\circ} 1-2$, pp. 1209-1218.

[22] A. Shokrani, V. Dhokia, y S. T. Newman (2012). «Environmentally conscious machining of difficult-to-machine materials with regard to cutting fluids», International Journal of Machine Tools and Manufacture, vol. 57, pp. 83101.

[23] Franck Girot y Esther Gutiérrez, «Desarrollos en la automatización del taladrado de estructuras aeronáuticas», Interempresas. Available from: https://www.interempresas.net/Aeronautica/Articulos/143203-Desarrollos-en-laautomatizacion-del-taladrado-de-estructuras-aeronauticas.html. Accessed: 2018-10-07.

[24] Zephyr Tool Group, «ZT507C Super Shaver». Available from: http://zephyrtoolgroup.com/. Accessed: 2018-10-07. 